\title{
Contrasting Student Attitudes Toward Study Abroad Programs Among College Of Business Majors
}

\author{
Ann T. Kuzma, Minnesota State University, Mankato, USA \\ John R. Kuzma, Minnesota State University, Mankato, USA \\ Harold F. Thiewes, Minnesota State University, Mankato, USA
}

\begin{abstract}
The evolution of globalization has increased the demand for skills that can compete in the expanding global markets. In addition to meeting the basic skills required in particular academic disciplines, many educators have advocated that an increased international exposure should be included in students' higher educational experience. Some universities include international study abroad as a component of their degree requirements. Our study surveyed junior and senior level business students at a publicly-funded state university to determine their attitudes toward the study abroad experience. This university does have various study abroad experiences available to students through its International Center and encourages, but does not require, an international experience for graduation. Our study contrasts the perceptions of a study broad experience between the business disciplines. We seek to further clarify this area of research by identifying differences in the majors' perceived value of the study abroad experience relative to their in-class major courses, their financial needs, costs of studying abroad, concerns about safety when studying abroad, and their views of the value of the overall study abroad experience by potential employers.
\end{abstract}

Keywords: Globalization; Study Abroad; Business Students' Perceptions

\section{INTRODUCTION}

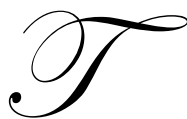

he globalization of business has increased the demand for college graduates with an international experience. In addition to teaching the basic skills required in particular academic disciplines, many educators have advocated that an increased international exposure should be included in students' higher educational experience. The increased exposure could include activities such as the study of an international language, more interaction with international students, or possibly traveling and study abroad. Further, many higher education institutions have encouraged faculty to engage in activities, such as international faculty exchanges, to enhance their appreciation of the global perspective. Some colleges and universities, such as the Carlson School of Management at the University of Minnesota, now require all of their undergraduates to participate in a study abroad program (Carlson School of Management, 2011).

\section{LITERATURE REVIEW}

\section{Growth of Study Abroad Programs}

The concept of the inclusion of foreign study or travel as part of a college student's undergraduate education is not new. As far back as the sixteenth century, young aristocrats included the so-called "Grand Tour" as part of their classical education. Wealthy young Englishmen, Germans, Scandinavians, and eventually Americans traveled to various points in Europe and the Middle East to be introduced to other cultures (Metropolitan Museum of Art, 2011). More recently, the Fulbright Program has supported the international exchange of university students and faculty through a U.S. government-sponsored program. Approximately 310,000 "Fulbrighters", 116,900 from 
the United States and 192,800 from other countries, have participated in the program since its inception in 1946. This program awards approximately 8,000 new grants every year and operates in over 155 countries (Fulbright International Educational Exchange Program, 2011).

The Institute of International Education (IIE), one of the organizations used to administer the Fulbright Program, recently reported that they expect to see a rise in the number of students studying abroad during the 2010/2011 academic year, after a slight downturn in previous years. IIE reported that 262,416 U.S. students studied abroad in the 2007/08 academic year. The student number dropped to 260,327 in the 2008/09 academic year (IIE, Open Doors Fast Facts, 2010). In a survey of college study abroad administrators during October 2010, more than half of the respondents indicated that their campuses experienced an increase in the number of students studying abroad in the 2009/10 academic year. The slight dip that was observed in 2008/09 was reflective of staff and study abroad budgets cuts that were made immediately following the economic crisis of 2007. The rebound appears to be due to steps that campuses have taken to strengthen participation in study abroad programs and to changes in the types of these programs that students are choosing. For example, more students are choosing shorter programs, less expensive programs, programs in which their financial aid can be used, and programs located in less expensive world regions (IIE, Snapshot Survey, 2010). Overall, U.S. student participation in study abroad programs has more than doubled over the past ten years (Summers, 2011).

\section{Where do students go and for how long?}

The leading destinations for U.S. study abroad participants continue to be the so-called "comfort zone" countries of the United Kingdom, Italy, Spain, and France. These four account for almost 40 percent of the total. China is now fifth in popularity, surpassing Australia. The IIE reports that Argentina, South Africa, Chile, Netherlands, Denmark, Peru and South Korea have experienced double-digit growth from the 2007/08 to 2008/09 academic years. Overall, fifteen of the top twenty-five study abroad countries are outside Western Europe (IIE, Open Doors Fast Facts, 2010). The top fields of study for U.S. study abroad students are the social sciences, business/management, and the humanities (IIE, Open Doors Fast Facts, 2010).

Although the forms of study abroad can vary widely, most U.S. students choose programs that are shortterm. According to the IIE, nearly 55 percent of U.S. students study abroad in programs for a summer, a January term, or sessions of eight weeks or less during the academic year (IIE, Open Doors Fast Facts, 2010). Another 41 percent study abroad for a semester, or one or two quarters, and the remainder will pursue long-term study of an academic or calendar year (IIE, Open Doors Fast Facts, 2010). In addition to the time duration, other variables that define the form of study abroad program include whether courses are part of a degree program abroad or only intended for study abroad students, language used in class, faculty nationality, classmates' nationality, and housing type. Some students may participate in an internship program. As an example, an American student might be studying abroad for a semester, enrolled in a class taught in English by an American faculty member, often living in American student housing. This could be contrasted with the experience of an American student, living with a host family, and studying course material in the local language.

\section{Prior Research}

Unsurprisingly, the area of study abroad has been investigated for a number of years, over a variety of research issues. Memberships in professional associations, such as the National Association of Foreign Student Advisors, Association of International Educators, the Forum on Education Abroad, and the Council on International Educational Exchange demonstrate the commitment to studying abroad programs that has been embraced by colleges and universities worldwide. Publications such as Frontiers: The Interdisciplinary Journal of Study Abroad and the Journal of Studies in International Education focus on the various research topics associated with the impact of study abroad. Research topics include, but are not limited to: curriculum and program design; student preferences, expectations and perceptions; faculty involvement and preparation; financial considerations; institutional support ; career enhancement; recruitment strategies; and influences from family, friends, and fellow students. 
Much of the early research in this area was anecdotal in nature. Colleges and universities would report on their own experiences with study abroad programs and the means used to assess learning outcomes and student satisfaction (e.g. Ingraham and Peterson, 2004). More recently, Cory and Martinez (2009) suggested the use of a survey instrument, both pre- and post-study abroad, and recommended that students might be assessed throughout the program to remedy any problems the students might be experiencing. Over time, empirical research has increased to cover a range of issues. Moghaddam, Peyvandi and Wang (2009) examined the influence of students' personality traits on their overall satisfaction of a study abroad experience. Risk-taking propensity, goal orientation, and openness to experience were investigated for relationships to students' perception of study abroad. Only the goal orientation attribute showed a connection to how effective students viewed a study abroad experience. Bakalis and Joiner (2004), in an earlier study, also looked at students' predisposition to study abroad programs as being linked to personality dimensions. Specifically, students with a high degree of openness and a high tolerance of ambiguity were more likely to participate in an exchange program. In contrast, students with a low degree of openness and low tolerance of ambiguity were less likely to participate. Walker, Bukenya, and Thomas (2010) explored students' perceptions of study abroad programs at Historically Black Colleges and Universities (HBCUs) to provide some understanding of why less than one percent of undergraduate minority students participate in such programs. One of their findings suggested that the more an individual has studied economics and/or business, the more accepting and approving they are of globalization.

Another research stream examined the connection between students' majors or career goals with their predisposition to participate in study abroad. As stated earlier, business/management students rank second in the number of U.S. students in study abroad programs, or about 20 percent overall each year (IIE, Open Doors Fast Facts, 2010). Clearly, business students with an international immersion experience are in demand. According to the Economic Policy Institute, approximately 1.4 million jobs were created by U.S. companies overseas last year, compared with 1.0 million in the United States (Galuzka, 2011). To prepare students for this demand, Howard University's business school offers three global programs: the $21^{\text {st }}$ Century Advantage Program, the Center for Professional Development, and the Executive Leadership Honors Program. All have the goal of preparing students for careers abroad with U.S. or multinational companies, with finance and accounting being the most popular programs.

\section{THE STUDY}

This paper examines the student attitudes toward study abroad programs of 246 undergraduate College of Business students at a Midwestern state university during the fall semester of 2011. We gathered information regarding:

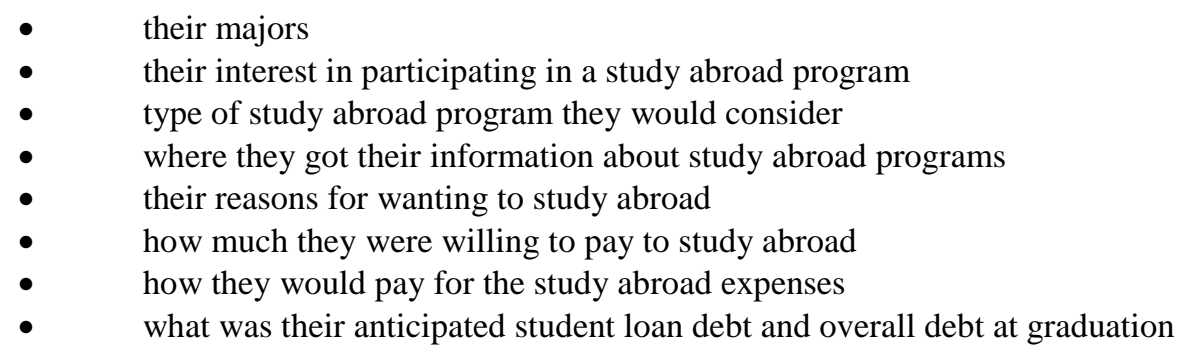

The surveys were separated into two groups. The Accounting and Finance (Acct/Fin) majors comprised one group and Marketing, Management, and International Business (Mrkt/Mgmt) majors comprised the other group. There were 123 students in each group.

The two groups were similar in terms of their academic standing and study abroad plans: the Acct/Fin group contained 18, 42 and 63 students and the Mrkt/Mgmt group contained 12, 51 and 60 students at the Sophomore, Junior and Senior levels, respectively. Seventy-four, or 60 percent of the Acct/Fin group and 81, or 66 percent of the Mrkt/Mgmt group answered that they had experienced some form of international travel. The most common destination listed by students as their foreign travel experience was Mexico. In terms of their intent to 
participate in a study abroad program, only four students from the Acct/Fin group and three students from the Mrkt/Mgmt group had previously participated in some form of study abroad program. Further, 13 students from the Acct/Fin group and 18 from the Mrkt/Mgmt group indicated they had plans to participate in a study abroad program at a future date. However, over 80 percent in each group indicated they had no plans to participate in a study abroad program.

In general, information sources were not highly successful in providing students with information on study abroad programs. Students were asked to rate the importance of information booths, the international programs office, the university website, bulletin boards and class announcements in terms of providing them with information on the study abroad programs available. On a 1 (very unimportant) to 5 (very important) Likert scale, all information sources were scored between 2.7 and 3, with class announcements receiving the highest (3.0) level of importance and the university sources, such as bulletin boards and university websites, receiving the lowest importance ranking.

Table 1: Type of Study Abroad Program

\begin{tabular}{ll}
\hline One to two week Study Abroad & 3.17 \\
One Semester Study Abroad & $3.05^{*}$ \\
One Year Study Abroad & $2.04^{*}$ \\
Summer Study Abroad & 2.91 \\
Internship in a Foreign Country & 2.84 \\
Would not consider Study Abroad & 2.52 \\
\hline
\end{tabular}

*Difference Significant at the .10 level

**Difference Significant at the .05 level

We then asked students to consider which type of international experience they might prefer. Again, a Likert scale of 1 (strongly disagree) to 5 (strongly agree) was utilized. Of the two groups, 39 or 32 percent of the Acct/Fin respondents and 30 or 24 percent of the Mrkt/Mgmt respondents expressed either agreement or strong agreement to the statement that they would NOT consider a study abroad program. Table 1 shows the results and mean responses. Only two questions - preference for a one-semester or one-year study abroad program - revealed significant differences and only at the .10 significance level. In both of these study abroad options and the general willingness to participate in a study abroad program, the Mrkt/Mgmt group exhibited a more favorable willingness to participate in these experiences. Further, a shorter experience, such as a one or two-week or a one-semester experience, was the preferred option.

Once we established student preferences on their general willingness to study abroad and their preferred time horizon, we asked the students to rate their perceptions of various attributes involved in the study abroad experience. Again, a five-point Likert scale requesting their agreement or disagreement to the statements was used. A listing of the attributes and mean score is presented in Table 2. Students generally were in strong agreement to many of the attribute statements, feeling it would enhance cultural understanding, broaden perspectives, provide the travel opportunity, and allow them to meet new friends and contacts. The Mrkt/Mgmt group was in stronger agreement, with a significant difference at the .05 level, to the statement that the experience would allow them the ability to meet new friends and contacts. What is of particular interest is that, although there was general disagreement to the statement that the experience would add very little to one's resume, the Acct/Fin group's mean response exhibited significantly less disagreement, significant at the .05 level, to the statement that it would add little to one's resume. Overall, results of these questions suggest the Mrkt/Mgmt group perceived a stronger belief in the value of the study aboard experience to their future career prospects. However, both groups were in general agreement that the cost could be too high. While both groups were in general agreement that the experience would have an influence on their employment, surprisingly the Acct/Fin respondents had a stronger belief that the study abroad experience would add little to their resume. 
Table 2: Reasons for Studying/Not Studying Abroad

\begin{tabular}{ll}
\hline Greater Understanding/Appreciation of Another Culture & 4.16 \\
Broaden Perspective & 4.11 \\
Opportunity to Travel & $4.36^{*}$ \\
New Friends and Contacts & $4.08^{* *}$ \\
Parent Concern for Safety & $2.93^{*}$ \\
Delay my Graduation & 3.50 \\
Cost Too Much Money & 4.09 \\
Influence on my Employment & 3.84 \\
Add Very Little to my Resume & $1.94 * *$ \\
\hline
\end{tabular}

*Difference Significant at the .10 level

$* *$ Difference Significant at the .05 level

We then asked the students to list the three most important attributes from Table 2 that would influence their study abroad experience. In terms of the number selecting a primary reason for studying abroad, both groups ranked their top three reasons in identical order. Not surprisingly, the vast majority of students, $40 \mathrm{Acct} / \mathrm{Fin}$ and 39 Mrkt/Mgmt students listed the "cost too much money" attribute as the primary reason for not studying abroad. The second most selected primary reason was the belief that the experience would "give me a greater understanding/appreciation of another culture" (22 Acct/Fin and $28 \mathrm{Mrkt} / \mathrm{Mgmt}$ students). The third most selected reason involved the "delay my graduation" attribute (18 Acct/Fin and $11 \mathrm{Mrkt} / \mathrm{Mgmt}$ students). Thus, even though students rated attributes such as "broadening one's perspective" and "opportunity to travel" extremely high in the Likert scale ranking, neither of the two attributes were ranked highly, in terms of the top three primary reasons for studying/not studying abroad.

Lastly, we asked students to provide information regarding their financial status. Specifically, we provided students with five categories ranging from less than $\$ 2,000$ to over $\$ 10,000$ and asked them to check the category listing the amount of additional cost that they would be willing to pay to participate in a study abroad program. Two hundred and nine students, or 85 percent of the sample, stated they would be willing to spend less than $\$ 3,500$. Not one student expressed a willingness to spend more than $\$ 10,000$ for a study abroad experience. We also asked students to list their anticipated student loan debt upon graduation. Two hundred and eighteen of the 246 students answered this question. Eighty of the 218 or 37 percent expected to have less than $\$ 10,000$ of student loan debt while 39 or 18 percent expected their student loan debt to exceed $\$ 30,000$. The remaining 99 students expected their student loan debt to fall between $\$ 10,000$ and $\$ 30,000$. Our intent in asking these questions was to ascertain if both the expected cost of the study abroad program and the students' expected student loan debt were impacting their view of the reasons in selecting the study abroad attributes. Accordingly, we conducted a correlation analysis between the income levels and the rankings of the nine attributes presented in table 2 .

Table 3: Attribute and Cost Correlations

\begin{tabular}{lrrrrrrrrrr}
\hline & Und & Per & Trav & Frnds & Safety & Grad & Cost & Employ & Resume & ExpCst \\
\hline Understanding & 1.0 & & & & & & & & & \\
Perspective & 0.794 & 1.0 & & & & & & & & \\
Travel & 0.620 & 0.655 & 1.0 & & & & & & & \\
New Friends & 0.635 & 0.618 & 0.703 & 1.0 & & & & & & \\
Safety Concern & 0.256 & 0.230 & 0.181 & 0.222 & 1.0 & & & & & \\
Delay Grad & 0.092 & 0.078 & 0.131 & 0.165 & 0.250 & 1.0 & & & & \\
Cost Too Much & 0.141 & 0.124 & 0.170 & 0.090 & 0.204 & 0.403 & 1.0 & & & \\
Influ Emplymt & 0.423 & 0.438 & 0.435 & 0.431 & 0.150 & 0.084 & 0.203 & 1.0 & & \\
Add to Resume & -0.238 & -0.206 & -0.221 & -0.279 & 0.067 & 0.205 & 0.101 & -0.243 & 1.0 & \\
Exp Cost & 0.198 & 0.203 & 0.170 & 0.203 & -0.062 & -0.104 & -0.344 & 0.063 & -0.174 & 1.0 \\
Stud Debt & -0.008 & 0.034 & -0.029 & -0.083 & -0.048 & -0.075 & 0.044 & -0.003 & 0.022 & -0.094 \\
\hline
\end{tabular}

Correlation results of the nine attributes in Table 2 and the expected study abroad cost and student's expected student loan debt upon graduation are presented in Table 3. Not surprisingly, extremely high correlations were observed, ranging from .618 to .794, between the understanding/appreciation of another culture, the 
broadening of individual perspectives, the opportunity to travel, and the making of new friends/contacts attributes. Further, there was a high correlation between these four variables and the belief that the experience would have an impact on one's employment prospects, with the employment influence variable correlating at approximately .43 with each of the four attributes. Further, it is interesting to note that there is a positive correlation, ranging between .170 and .2033 , between the cost the students were willing to pay and the value of these four attributes; simply, the higher the expected value of the experience, the greater the amount that students were willing to pay.

Of further interest is that none of the nine attributes reached a correlation stronger than -.083 between the students' expected student loan debt and any of the nine attributes. Weak negative correlation (-.094) was documented between the students' expected student loan debt and the additional cost they were willing to pay to participate in the study abroad program. Thus, higher levels of expected student loan debt may negatively impact their willingness to assume more debt for the study abroad experience. However, a surprising result is revealed in the correlation result between the students' willingness to pay and the belief the experience cost too much. To repeat, the amount of students' expected student loan debt essentially does not correlate $(+.044)$ with the "cost too much" attribute, but there is a negative correlation (-.344) between the students' willing to pay and the ranking of the "cost too much" attribute. Thus, the more a student is willing to pay, the less is the belief that the experience is too expensive. This result might suggest that it would be beneficial for study abroad programs to put more emphasis on the study abroad programs' attributes and program costs, as many students do feel there is a definite value to the experience, while others are willing to spend very little and yet feel the cost are too high.

\section{CONCLUSION}

The majority of business students preferred a study abroad experience that lasted eight weeks or less. A one to two-week study abroad experience is the time frame that would be most desirable for most students. Marketing and Management majors were more open to a one-semester or one-year experience than Finance and Accounting majors. The majority of students expected the additional cost for the study abroad experience to be less than $\$ 3,500$.

Although all the students were in high agreement that the study abroad experience provided great value, the Marketing and Management majors rated the opportunity to travel and meet new friends higher than the Accounting and Finance majors. The students agreed that the experience would influence their employment but disagreed about the value the experience would add to their resumes. Accounting and Finance majors thought the experience would add less value to their resumes.

Overall, it was thought that universities could do a better job of communicating the importance of the study abroad experience to the students' development, the accessibility to study abroad opportunities, and the expenses associated with the various opportunities. It is important that these factors are communicated in a better fashion because the programs' perceived value is negatively related to the students' willingness to pay for the experience.

\section{AUTHOR INFORMATION}

Dr. Ann Kuzma received her Ph.D. in Marketing from the Kent State University in 1989. She has taught at Minnesota State University from 1989 until the present and currently serves as Department Chairperson. E-mail: ann.kuzma@mnsu.edu

Dr. John Kuzma received his Ph.D. in Marketing from the Kent State University in 1990. He has taught at Minnesota State University from 1989 until the present and is currently the Director of the Center for Sales Excellence at Minnesota State University, Mankato. E-mail: john.kuzma@mnsu.edu

Dr. Harold Thiewes received his Ph.D. in Finance from the University of Iowa in 1990. He has taught at Minnesota State University and the University of Iowa from 1980 until the present and has previously served as Department Chairperson. E-mail: harold.thiewes@mnsu.edu. Corresponding author. 


\section{REFERENCES}

1. Bakalis, Steve and Therese A. Joiner (2004). "Participation in tertiary study abroad programs: the role of personality," International Journal of Educational Management, 18(5), 286-291.

2. Carlson School of Management, University of Minnesota, "International Experience," from http://www.csom.umn.edu/undergraduate/academics/international-experience.html. Retrieved 9/28/2011.

3. Cory, Suzanne N. and Zaida Martinez (2008). "Student perceptions of study abroad opportunities: are we achieving our goals? An exploratory study," $14^{\text {th }}$ Annual World Forum, Colleagues in Jesuit Business Education, International Association of Jesuit Business Schools, Business and Education in an Era of Globalization: The Jesuit Position, July 20-23, 2008.

4. "Fulbright International Educational Exchange Program," U.S. Department of State, Bureau of Educational and Cultural Affairs, from http://fulbright.state.gov/about.html. Retrieved 9/29/2011.

5. Galuzka, Peter (2011). "Aspiring business students with international immersion experience in high demand," Diverse Issues in Higher Education (July 13, 2011) from http://diverseeducation.com/cache/print.php?articleId=16051. Retrieved 9/22/2011.

6. Ingraham, Edward C. and Debra Peterson (2004). "Assessing the impact of study abroad on student learning at Michigan State University," Frontiers: The Interdisciplinary Journal of Study Abroad, 10, 83100 .

7. Institute of International Education, Fall 2010 Study Abroad Snapshot Survey, "Campuses report early indication that study abroad is rising," from http://www.iie.org/Who-We-Are/News-and-Events/PressCenter/Press-Releases/2010/2010-11-15-Fall-2010-International-Student-Enrollment-Survey.

8. Institute of International Education, "Open Doors 2010 Fast Facts," from http://www.iie.org/opendoors. Retrieved 9/22/2010.

9. Metropolitan Museum of Art, "Heilbrunn Timeline of Art History: The Grand Tour," from http://metmuseum.org/toah/hd/grtr/hd_grtr.htm. Retrieved 9/28/2011.

10. Moghaddam, J.M. Peyvandi, Ali, and Jia Wang (2009). "The effect of personality traits on the perceived effectiveness of summer study abroad programs: an empirical study in the United States," International Journal of Management, 26(3), 426-435.

11. Summers, Nick (2011). "Party hard, study harder: the stakes are getting higher for U.S. college students in programs abroad - and it's not just about going wild overseas," Newsweek, 158 (12), 18.

12. Walker, Stevon, Bukenya, James O., and Terrance Thomas (2010). "Examining students' perceptions of globalization and study abroad programs at HBCUs," Selected paper prepared for presentation at the Southern Agricultural Economics Association Annual Meeting, Orlando, Florida, February 6-9, 2010. 
NOTES 